\title{
Shiva Gupta*
}

Himani Sharma

\section{Supreet Thind}

\section{Rasveen Kaur}

Assistant Professor, Department Of Periodontology, Mm College Of Dental Sciences And Research, Mullana (Ambala) - $13320{ }^{*}$ Corresponding Author

Assistant Professor, Department Of Periodontology, School Of Dental Sciences, Sharda University, Noida.

Assistant Professor, Department Of Periodontology, Mm College Of Dental Sciences And Research, Mullana (Ambala) - 133207

Assistant Professor, Department Of Periodontology, Mm College Of Dental Sciences And Research, Mullana (Ambala) - 133207

ABSTRACT Mucocele is defined as mucus-filled cavity, which can appear in the oral cavity, appendix, gallbladder, paranasal sinuses, and lacrimal sac. They are mostly benign and self-limiting nature. The lesion is formed when the main duct of a minor salivary gland is torn followed by extravasation of the mucus into the fibrous connective tissue so that a cyst like cavity is produced. The most common site of occurrence is lower lip and most probably affects the young patients. These are soft, fluctuant, transparent cystic swelling of deep blue colour. Surgical removal of the mucocele is the treatment of choice. This paper reviews the Mucocele and presents a case reports.

KEYWORDS : Extravasation, Mucocele, Oral Mucosa, Retention, Trauma

\section{INTRODUCTION}

Oral mucocele also termed as mucous retention cyst, mucous extravasation cyst and mucous cyst of the oral mucosa is a major and more commonly, the minor salivary gland lesion of traumatic origin.[1] Mucocele is the 17th most common salivary gland lesions seen in the oral cavity which are usually formed due to rupture of an excretory duct of a salivary gland, which leads to an outpouring of saliva into the surrounding tissues.[2,3] Mucoceles are subdivided into two types: I. Mucus extravasation type, which occurs because of a ruptured salivary gland duct usually caused by trauma, like lip biting. II. Mucus retention type, which results from the obstruction of the duct of a minor and/or accessory salivary gland.[4]

Mucoceles may appear anywhere in the oral mucosa such as lips, cheeks and the floor of the mouth, but mainly appears on the lower lip and are rarely seen on the upper lip, retromolar pad or palate.[5] Although they may occur at any age but are most frequently in the second and a third decade of life. The lesion is more frequently found in children, adolescents and young adults with no sex predilection.[6] Mucoceles appear as small, rounded, discrete, translucent, soft and fluctuant bluish-coloured lesion of variable size. Usually they are painless and have a tendency to relapse.[7] If these are left untreated, an episodic increase and decrease in size may be observed, based on rupture and subsequent mucin production.

This case report presents surgical removal of mucocele using a simple surgical technique along with literature review to enhance the knowledge of the general dental practitioner.

\section{CASE REPORT}

A 21 year-old male patient came to the Department of Periodontology, Subharti Dental College \& Hospital, Meerut with a chief complaint of swelling in the inner aspect of lower lip in 42,43 region. The history of present illness dates back 2 months since the patient has seen the swelling which is progressively increasing but is painless. Past dental and medical history reported by the patient had no findings of particular relevance to this dental examination.

Intra-oral examination revealed an oval shaped, creamish white in colour, soft in consistency, non tender, fluctuant and palpable lesion on the inner labial mucosa.(Figure 1) Routine blood investigations were carried out and the values were in the normal range. On the basis of history and clinical examination a provisional diagnosis of mucocele was made. The treatment involved surgical resection of the tissue. The surgical procedure was explained to the patient and an informed consent was obtained. The mucocele was removed under infiltrating local anaesthesia (2\% lidocaine with epinephrine 1:80,000; one cartridge). A vertical incision was placed to split the overlying mucosa and then to avoid reoccurrence the mucocele was resected from the base followed by placement of sutures.(Figure 2,3,4) The patient was recalled after one week to evaluate healing which was found to be uneventful. The excised specimen was sent for routine histopathological examination.

The histopathological report revealed hyperplastic parake ratinized stratified squamous epithelium with an underlying fibro-cellular connective tissue stroma. The stroma shows mucin filled spaces adjacent to the epithelium with surrounding mixed inflammatory infiltrate and haemorrhage. Deeper areas of the section reveal salivary gland acini and ducts.(Figure 5) Hence, a final diagnosis of Extravasation type mucocele was made. Patient was recalled after 3 months to check for any reoccurrence of the lesion.(Figure 6)

\section{DISCUSSION}

Mucoceles are mucus containing cystic lesions of the minor salivary glands. In general population, the prevalance of mucocele is 2.4 cases per 1000 people with barely any difference between males and females.[8] According to the data collected on 2,339 cases of mucocele by The Armed Forces Institute of Pathology, 33.0\% of mucocele occurred on the lower lip, $7.7 \%$ on the buccal mucosa, $6.3 \%$ on the floor of the mouth, $6.1 \%$ on the tongue and only $0.4 \%$ on the upper lip.[9] Mucoceles have been reported to occur in the second and third decades of life, especially in young individuals, with $70 \%$ of them being younger than 20 years. [8]

The main etiological factors of mucocele reported in literature are traumatism, oral habits such as lip biting/sucking and obstruction of salivary gland duct.[10] In the present case also trauma from the malpositioned teeth was identified as 
the cause of lesion.

On clinical presentation, a mucocele appears as an asymptomatic fluid filled vesicle or blister in the superficial mucosa with bluish to translucent hue or as a fluctuant nodule deep within the connective tissue having normal mucosal coloration, however, bleeding into the swelling may impart a bright red and vascular appearance. Fibrosis may be seen on the surface of long standing lesions. About $75 \%$ of the lesions are smaller than $1 \mathrm{~cm}$ in diameter, although the size may range from a few millimetres to a few centimeters. The various differential diagnosis of mucocele are Blandin and Nuhn mucocele, minor apthous ulcer, lipoma, oral hemangioma, oral lymphangioma and soft tissue abscess.[11]

Histopathologically, mucocele is of two types extravastion (most common type) and retention type. Microscopically, hyperplastic parakeratinized stratified squamous epithelium may be seen with small cystic spaces containing mucin and mucus-filled cells, areas of spilled mucin surrounded by a granulation tissue and sebaceous cells in the connective tissue. Presence of salivary gland tissue and sialomucin is diagnostic. In the present case report, the mucocele is extravasation type.

The final diagnosis of superficial mucocele is usually made by the history and clinical findings. As appearance of mucocele is pathognomonic, therefore, certain crucial factors are considered before the final diagnosis is made such as history of trauma, bluish colour and consistency, location of the lesion, variations in size and rapid appearance.[12]

Palpation can be helpful for a correct differential diagnosis as lipomas and tumors of minor salivary glands present no fluctuation while cysts, mucoceles, abscess, and hemangiomas show fluctuation. Radiographic evaluation may also be considered if sialoliths are contributing factor in the formation of oral and cervical ranulas. Fine needle aspiration may be done to demonstrate mucus retention phenomenon and inflammatory cells and high amylase and protein content can be revealed in chemical analysis. Computed tomography scanning and magnetic resonance imaging may be used to localize and determine the origin of the lesion. Evaluation of the lesion may also be done by ultrasonography using high-frequency transducers, ultrasound demonstrates the internal structures more clearly than computed tomography (CT).[13]

Mucocele is treated by complete excision of the lesion. Small mucoceles can be removed completely with the marginal glandular tissue before suture whereas larger mucoceles are marsupialized although it may cause recurrence but it is done in order to avoid damage to vital structures. Other approaches that can also been used for the treatment of the conventional mucocele with variable success are laser ablation, electro surgery, cryosurgery, intra-lesional injection of sclerosing agent OK-432 or steroid injection.[14,15] In the present case report the lesion was completely excised by conventional technique and the specimens were sent for histopathological evaluations.

\section{CONCLUSION}

Mucocele is the most common lesion of the oral mucosa that are painless and intransmissible but can affect regular eating and speaking routine of patients. Trauma is the usual cause and the most frequent location is the mucosa of the lower lip. The lesion is primarily diagnosed on the basis of clinical findings, however, a definitive diagnosis is based on the histopathological investigations. As recurrence has been associated therefore, complete excision of the lesion is treatment of choice. In the present case report, patient was recalled after 3 months for re-evaluation, excellent prognosis

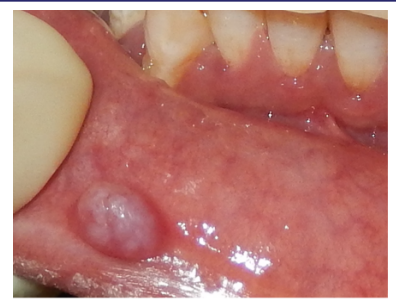

Figure 1: Pre-operative View

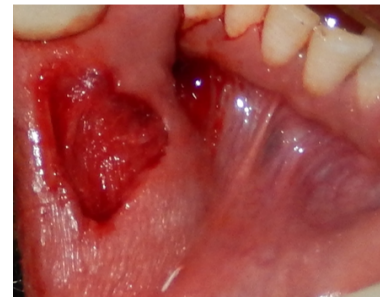

Figure 3: Complete

Excision of the lesion

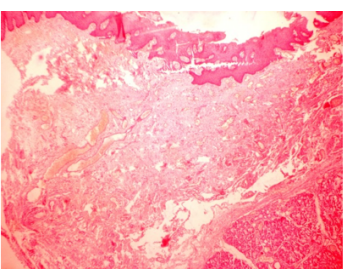

Figure 5:

Histopathological view

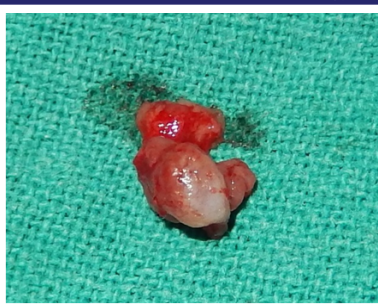

Figure 2: Surgically

Excised lesion

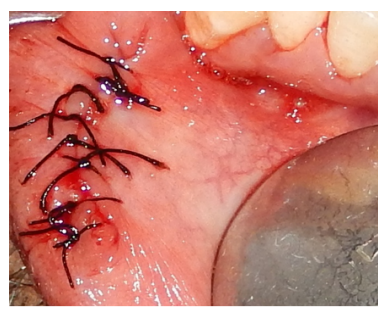

Figure 4: Sutures Placed

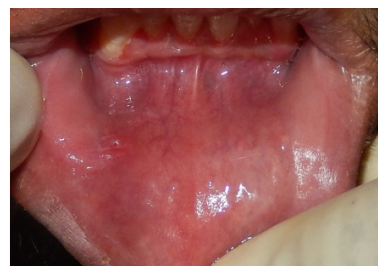

Figure 6: Three months post-operative view

\section{REFERENCES}

1. Rapini, Ronald P; Bolognia, Jean L.; Jorizzo, Joseph L. (2007). Dermatology: 2Volume Set. St. Louis: Mosby. ISBN 1-4160-2999-0.

2. Flaitz CM, Hicks JM. Mucocele and Ranula. eMedicine; 2015.

3. Regezi JA, Sciubba JJ. Salivary gland diseases. In: Oral pathology: clinical pathologic correlations. lst ed. Philadelphia (PA): W.B. Saunders Co.; 1989. p. 225-83.

4. Baurmash HD. Mucoceles and ranulas. J Oral Maxillofac Surg 2003;61:369-78.

5. Cohen L. Mucoceles of the oral cavity. Oral Surg Oral Med Oral Pathol 1965; 19:365-72.

6. Mc Donald, Avery \&Dean: Dentistry for the child and adolescent, Eight edition, Mosby, 2004

7. Bermejo A, Aguirre JM, López P, Saez MR. Superficial mucocele: Report of 4 cases. Oral Surg Oral Med Oral Pathol Oral Radiol Endod 1999;88:469-72.

8. Senthilkumar B, Mahabob MN. Mucocele: An unusual presentation of the minor salivary gland lesion. J Pharm Bioall Sci 2012;4:180-2.

9. Ellis GL, Auclair PL, Gnepp DR, editors. Obstructive disorders. In: Surgical pathology of the salivary glands. Philadelphia (PA): W.B. Saunders Co.; 1991. p. 26-38.

10. Nallasivam KU, Sudha BR. Oral mucocele: Review of literature and a case report. J Pharm Bioall Sci 2015:7:S731-3.

11. Jinbu Y, Itoh H. Mucoceles of the glands of blandin-nuhn: Clinical and histopathologic analysis of 26 cases. Oral Surg Oral Med Oral Pathol Oral Radiol Endod 2003;95:467-70.

12. Andiran N, Sarikayalar F, Unal OF, Baydar DE, Ozaydin E. Mucocele of the anterior lingual salivary glands: From extravasation to an alarming mass with a benign course. Int J Pediatr Otorhinolaryngol 2001;61:143-7.

13. Yamasoba T, Tayama N, Syoji M, Fukuta M. Clinicostatistical study of lower lip mucoceles. Head Neck 1990;12:316-20.

14. More CB, Bhavsar K, Varma S, Tailor M. Oral mucocele: A clinical and histopathological study. J Oral Maxillofac Pathol 2014;18, Suppl S1:72-7.

15. S Gupta, R Arora, A Sharma, S Gupta. Giant Cell Soft Tissue Tumour of Maxilla. International Journal of Oral Health Dentistry, 2015; 1(4):194-196. 